\title{
The Network of Knowledge approach: improving the science and society dialogue on biodiversity and ecosystem services in Europe
}

\author{
Carsten Nesshöver ${ }^{1}$ (D) Marie Vandewalle ${ }^{1}$ - Heidi Wittmer ${ }^{2}$. \\ Estelle V. Balian ${ }^{4}$ Esther Carmen ${ }^{17}$ - Ilse R. Geijzendorffer ${ }^{5,6}$. \\ Christoph Görg ${ }^{3,7} \cdot$ Rob Jongman $^{5}$ - Barbara Livoreil ${ }^{8,9}$ • \\ Luis Santamaria $^{10} \cdot$ Stefan Schindler $^{11,12} \cdot$ Josef Settele $^{3,13}$. \\ Isabel Sousa Pinto ${ }^{14} \cdot$ Katalin Török $^{15} \cdot$ Jiska van Dijk $^{16}$. \\ Allan D. Watt ${ }^{17} \cdot$ Juliette C. Young $^{17}$ - Klaus Peter Zulka ${ }^{12,18}$. \\ the KNEU Project Team
}

Received: 27 November 2015/Revised: 8 April 2016/Accepted: 7 May 2016/

Published online: 14 June 2016

(C) The Author(s) 2016. This article is published with open access at Springerlink.com

\begin{abstract}
The absence of a good interface between scientific and other knowledge holders and decision-makers in the area of biodiversity and ecosystem services has been recognised for a long time. Despite recent advancements, e.g. with the Intergovernmental
\end{abstract}

Communicated by David Hawksworth.

This is part of the special issue on Networking Biodiversity Knowledge.

Team of the KNEU Project is provided in acknowledgement section.

Carsten Nesshöver

carsten.nesshoever@ufz.de

1 Department of Conservation Biology, UFZ-Helmholtz Centre for Environmental Research, UFZ Science-Policy Expert Group, Permoserstr.15, 04318 Leipzig, Germany

2 Department of Environmental Politics, UFZ-Helmholtz Centre for Environmental Research, UFZ Science-Policy Expert Group, Permoserstr. 15, 04318 Leipzig, Germany

3 Department of Community Ecology, UFZ-Helmholtz Centre for Environmental Research, UFZ Science-Policy Expert Group, Theodor-Lieser-Str. 4, 06120 Halle, Germany

4 Royal Belgian Institute of Natural Sciences (RBINS), Brussels, Belgium

5 Alterra, Wageningen University and Research Centre, P.O. Box 47, 6700 AA Wageningen, The Netherlands

6 Institut Méditerranéen de Biodiversité et d'Ecologie marine et continentale (IMBE) Aix Marseille Université, CNRS, IRD, Avignon Université, Technopôle Arbois-Méditerranée, 13545 Aix-en-Provence, France

7 Present Address: Institute of Social Ecology, University of Klagenfurt, Schottenfeldgasse 29, 1070 Vienna, Austria

8 Centre for Evidence Based Conservation, Bangor University, Bangor, Gwynedd LL57 2DG, UK 
Platform on Biodiversity and Ecosystem Services (IPBES), challenges remain, particularly concerning the timely provision of consolidated views from different knowledge domains. To address this challenge, a strong and flexible networking approach is needed across knowledge domains and institutions. Here, we report on a broad consultation process across Europe to develop a Network of Knowledge on biodiversity and ecosystem services (NoK), an approach aiming at (1) organising institutions and knowledge holders in an adaptable and responsive framework and (2) informing decision-makers with timely and accurate biodiversity knowledge. The consultation provided a critical analysis of the needs that should be addressed by a NoK and how it could complement existing European initiatives and institutions at the interface between policy and science. Among other functions, the NoK provides consolidated scientific views on contested topics, identification of research gaps to support relevant policies, and horizon scanning activities to anticipate emerging issues. The NoK includes a capacity building component on interfacing activities and contains mechanisms to ensure its credibility, relevance and legitimacy. Such a network would need to ensure credibility, relevance and legitimacy of its work by maximizing transparency and flexibility of processes, quality of outputs, the link to data and knowledge provision, the motivation of experts for getting involved and sound communication and capacity building.

Keywords Science-policy-interface - European policy - Research networking - IPBES · Participatory methods $\cdot$ Information and data mobilisation

\section{Introduction}

Policy development related to biodiversity and ecosystem services conservation, management and use, requires availability of credible, timely and relevant scientific knowledge. Such claims are based on the perception that policies and decision-making are sometimes not adequately informed by existing knowledge, or that the processes to make

9 Present Address: Foundation for Research on Biodiversity (FRB), 195 rue Saint Jacques, 75005 Paris, France

10 Doñana Biological Station (EBD-CSIC), C/Americo Vespucio s/n, Isla de la Cartuja, 41092 Seville, Spain

11 Department of Conservation Biology, Vegetation \& Landscape Ecology, University of Vienna, Rennweg 14, 1030 Vienna, Austria

12 Environment Agency Austria, Spittelauer Lände 5, 1090 Vienna, Austria

13 German Centre for Integrative Biodiversity Research (iDiv) Halle-Jena-Leipzig, Deutscher Platz 5e, 04103 Leipzig, Germany

CIIMAR-Interdisciplinary Centre for Marine and Environmental Research and Faculty of Sciences University of Porto, R. dos Bragas, 289, 4050-123 Porto, Portugal

15 MTA Centre for Ecological Research, Institute of Ecology and Botany Vácrátót, Alkotmány u. 2-4, Vácrátót 2163, Hungary

16 Norsk Institutt for Naturforskning (NINA), 7485 Trondheim, Norway

17 NERC-CEH Edinburgh, Bush Estate, Penicuik EH26 0QB, UK

18 Department of Integrative Zoology, University of Vienna, Althanstr. 14, 1090 Vienna, Austria 
such knowledge available to policy- and decision-makers are insufficiently structured. A good example for this is the recent discussion on the effect of neonicotinoid pesticides on bees and other pollinators, where interests from society strongly interfered with the synthesis of potentially relevant knowledge (Walters 2013; van der Sluijs et al. 2015). At the same time, biodiversity and ecosystem services issues are complex and often influenced by a multitude of drivers and pressures, which require a broad array of knowledge to understand and address them (Spierenburg 2012; Young et al. 2013; Young et al. 2014).

Although a number of established approaches to synthesize scientific knowledge on specific issues exist (e.g., Pullin and Stewart 2006; Pullin et al. 2009; Sutherland et al. 2014; Dicks et al. 2014), and a number of institutions and processes (e.g. Service contracts) provide knowledge for policy processes, these rarely include the variety of existing knowledge and its holders. Consequently, networking and communication components are not adequately reflected in many existing science-policy-interfaces (SPI). Here we define SPIs quite broadly as organizations, initiatives or projects that work at the boundary of science, policy and society to enrich decision making, shape their participants' and audiences' understandings of problems, and eventually produce outcomes regarding decisions and behaviours (Sarkki et al. 2015). More flexible approaches that complement and enrich the available scientific evidence by taking into account the changing needs and constraints of knowledge users, as well as their own knowledge are needed (Sarkki et al. 2013; Nesshöver et al. 2014; Young et al. 2014). In this context, the work carried out within the scientific community and jointly with other actors can increasingly be understood as an interfacing activity between knowledge domains, rather than a mere translation of knowledge from providers to requesters (Funtowicz and Ravetz 1994; Pielke 2007).

To address the challenge of improving the SPI on biodiversity and ecosystem services, we developed the Network of Knowledge (NoK) approach to provide a better linkage and organisation of the knowledge-holder community to render it more capable to respond to knowledge needs from decision-making. The Network of Knowledge concept originated in the guidelines proposed by the European Platform for Biodiversity Research Strategy (EPBRS) of "bringing together existing organisations and processes in a flexible, responsive and broad-based way [...] helping to focus the support of science and scientists on the needs of those setting policy and taking decisions" through "temporary, ad hoc associations of diverse organisations to assemble and communicate knowledge adapted to the needs of clients” (EPBRS 2009). The concept was further developed in a broad consultation with knowledge holders and decision-makers across Europe. Here we present this iterative consultation process and, as a result of this process, identify the criteria and challenges, which should be addressed by a NoK approach.

We do this by following the key questions of the consultation process:

(1) How is the landscape of knowledge on biodiversity and ecosystem services in Europe currently shaped, and what are the current policy needs-in terms of SPI activities? (Section 3);

(2) Which functions should a Network of Knowledge provide to complement the existing institutions? (Section 4)

(3) What are the main challenges in establishing such a networking approach in a flexible and transparent way? (Section 5)

(4) How could it ensure that knowledge holders and decision-makers share their knowledge mutually in a credible, relevant and legitimate way? (Section 5)

With addressing these questions, we critically analysed the potential added value required of a networking approach in the current science-policy landscape in Europe. 


\section{Methods and approach used}

We carried on an iterative process to develop and test a Network of Knowledge on Biodiversity and Ecosystem Services in Europe and address the questions outlined above. Core elements were broad consultation activities with individuals or groups of experts from research, research networks, policy and practice. Throughout the project in total over 400 experts participated actively. Their composition included about $75 \%$ of scientists from different fields and backgrounds (universities and research institutes across Europe), $15 \%$ practitioners (e.g., from NGOs and management agencies)l, and $10 \%$ policy makers. Both groups included actors from the European (e.g., Directorates General on Environment and on Research and Innovation, European NGOs) as well as the national level (e.g., national agencies, biodiversity managers).

The process started with an assessment of existing European science-policy interfaces on biodiversity and ecosystem services to obtain an overview on one hand of European knowledge holders. (Section 3.1). The assessment also served to sketch a preliminary set of functions that a Network of Knowledge should fulfil to complement existing SPIs (Sect. 4). This first assessment was based on an internal survey involving all partners in the KNEU project, who represent and are involved in a very broad set of networks and projects in Europe and on the national scale (see acknowledgements). Further insights about connections between knowledge holders were received from a number of targeted interviews using the Net-map approach (for results, see Hauck et al. 2015). The results were presented at regional workshops and at the KNEU first conference (see below) to gain additional information on the knowledge holder landscape, but we had to acknowledge that the number and diversity of knowledge holders in the $28 \mathrm{EU}$ countries was too broad and diverse to be properly mapped, so we focused on actors on the European level. To identify needs from the policy side, a number of interviews with policy makers and practitioners on the European level were conducted. Out of 45 experts contacted, 24 agreed to be interviewed (for details, see Balian et al. 2012).

The next step in the consultation were three regional workshops, which addressed potential challenges and needs for a networking approach, also taking into account regional perspectives. To initiate discussions, the project team had developed a set of functions and principles of the NoK and sorted potential challenges it might face. This included a preliminary list of functions, a number of ethical principles (see also Tremblay et al. 2016), and a dedicated process design on how policy requests could be addressed (Livoreil et al. 2016). These functions and principles were further discussed with actors across the knowledge landscape through an online-consultation, and a larger European conference. About 250 experts participated in these activities, which resulted in a preliminary "green paper" outlining how a NoK could work (Livoreil et al. 2012).

As an additional element of the consultation, the NoK approach as developed in the first step for the green paper was tested with three trial assessments on biodiversity topics with policy relevance: (1) Current trends in kelp forests in Europe and evidence that these trends will affect the ecosystems biodiversity and the provision of ecosystem services (Araújo et al. 2016); (2) Effectiveness of interventions aiming at manipulating non-crop habitat or landscape features to maintain or support natural (indigenous) population of pest control agents (Dicks et al. 2016); and (3) Impact of multifunctional floodplain management on biodiversity (Schindler et al. 2016b). These trial knowledge assessments delivered preliminary results on the specific research questions they dealt with (e.g. Schindler et al. 2014) as well as direct feedback on the applied functionality of the NoK. The test cases 
were independently evaluated by a separate team that regularly visited the meetings and workshops, and conducted interviews with participants (Carmen et al. 2015). The aim of the evaluation was to identify strengths, weaknesses and complementarities of the different methodologies used, and to gain further insights about potential challenges in conducting the knowledge reviews. About 100 experts were involved in this test phase.

The lessons learned from the trial assessments were used to advance the development of the Network of Knowledge green paper into a white paper (KNEU Team 2014) which was presented to an online consultation and discussed during a second KNEU conference with 80 participants (September 2013), and during the final project event at the European parliament (April 2014), mobilising in total about 250 experts who provided feedback on the proposed approach (results included in Sects. 4 and 5).

During the project, the notions of credibility, relevance and legitimacy (CRELE) were used as an analytic framework (van der Sluijs et al. 2010; Sarkki et al. 2013, 2015). These notions are widely accepted and used in analysing SPIs (Cash et al. 2003; Sarkki et al. 2013). Although separating the conceptual from the potentially practical perspective of these attributes is difficult (Heink et al. 2015), they were considered as a useful guiding framework for reflecting on the challenges faced by an SPI (e.g. in the Intergovernmental Platform on Biodiversity and Ecosystem Services, IPBES (UNEP 2010)):

- Credibility of the NoK is the perceived quality, validity and expertise of the people, processes and knowledge exchanged at the interface. It should be ensured by the rigour of the process, the skills of the participants and the transparency of all processes and decisions.

- Relevance or saliency, represent the responsiveness of the NoK to needs of policy and society, i.e. to the users of an interface activity.

- Legitimacy is the perceived fairness and balance of knowledge holders' perspectives within the SPI processes, including inclusiveness of all relevant stakeholders and fairness in treatment of diverging values, beliefs, and interests.

In addition to the above three attributes, independence (i.e. avoiding influence of specific groups e.g. from donors, political parties and vested interest groups) was considered important by many contributors to the various consultations. It was therefore added as a fourth attribute of the NoK framework, although it could as well be understood as part of legitimacy or credibility.

The following sections summarize the main insights obtained from the process of developing and testing the Network of Knowledge on Biodiversity and Ecosystem Services in Europe as well as the challenges arising from them with regard to its credibility, relevance and legitimacy.

\section{The current science-policy interface landscape for biodiversity and ecosystem services}

When discussing the need for new interfacing approaches, it is crucial to analyse and to understand the existing knowledge landscape and its potential gaps. Section 3.1 briefly summarizes the developments in the biodiversity and ecosystem services knowledge landscape in Europe based predominantly on scientific knowledge-holders. Section 3.2 addresses the needs of policy- and decision-makers, how the current landscape addresses them and which gaps remain. 


\section{The evolving science-policy interface landscape}

The analysis of European knowledge holders and science-policy interfaces in the field of biodiversity and ecosystem services showed a diversity of initiatives, some of which have an explicit mandate, others have an intrinsic, self-given motivation to provide policyrelevant knowledge, and there are those that have the potential to contribute but currently refrain from acting. Environmental and conservation agencies (e.g., the European Environment Agency), or the Joint Research Centre (Institute for Environment and Sustainability) have official mandates by the European Commission. In many European countries, advisory committees of governments and other authorities might play a role besides national agencies or academies. Often, especially in the case of the European Commission, environmental consultancies play a role in compiling existing knowledge on specific questions and policies. Additional policy-relevant knowledge emerges from research projects funded by the European Commission Framework Programs, particularly largescale data and knowledge infrastructures that represent the European contributions to broader international programmes such as the European EBONE and EUBON projects, which contribute to the global GEOBON program of biodiversity observation data ${ }^{1}$; (Hoffmann et al. 2014; Jongman 2013) and the long-term Ecological Research network (LTER). ${ }^{2}$ Large-scale projects addressing biodiversity and ecosystem services (e.g., ALARM (Settele et al. 2005), SCALES (Henle et al. 2010), OPENness and OPERAs) ${ }^{3}$; as well as projects funded by thematic European funding networks of national funders (ERANets), ${ }^{4}$ such as BiodivERsA (Durham et al. 2014), also actively engage in science-policy processes. Networks of Excellence (research networks formerly funded by Framework Programmes) such as ALTER-Net and EUROmarine ${ }^{5}$ continue to play an active role in networking in the landscape of knowledge holders in biodiversity and reaching out to policy. Since 1999, the European Platform for Biodiversity Research Strategy (EPBRS), a forum at which natural and social scientists, policy-makers and other stakeholders identify structured and strategically important biodiversity research, serves as an interface on research policy issues (Nesshöver et al. 2008). ${ }^{6}$ Learned societies on different levels are

\footnotetext{
${ }^{1}$ EBONE-European Biodiversity Observation Network, EU project in the 6th framework programme (http://www.wageningenur.nl/en/Expertise-Services/Research-Institutes/alterra/Projects/EBONE-2.htm); EUBON-Building the European Biodiversity Observation Network, EU project in the 7th framework programme (http://www.eubon.eu); GEO BON-The Group on Earth Observations Biodiversity Observation Network (http://www.geobon.org).

2 The European network of LTER sites (http://www.lter-europe.net/) and its national members is also part of an international network, ILTER (http://www.ilternet.edu/).

3 ALARM-Assessing Large scale Risks for biodiversity with tested methods, EU project in the 6th framework programme (http://www.alarmproject.net); SCALES—Securing the conservation of biodiversity across administrative levels and spatial, temporal, and ecological scales, EU project in the 7th framework programme (http://www.scales-project.net); OpenNESS-Operationalisation of Natural Capital and Ecosystem Services (http://www.openness-project.eu/), OPERAs-Ecosystem science for policy and practice http://operas-project.eu/), OpenNESS and OPERAs are EU projects in the 7th framework programme and jointly host the webplatform OPPLA (http://www.oppla.eu).

${ }^{4}$ For details on the ERA-Net scheme, see http://ec.europa.eu/research/fp7/index_en.cfm?pg=eranetprojects-home, for the ERA-Net BiodiERsA, see: http://www.biodiversa.org/.

5 ALTER-Net-A long-term biodiversity, ecosystem and awareness research network (http://www.alter-net. info/); EuroMarine-Integration of European Marine Research Networks of Excellence (http://www. euromarineconsortium.eu/); both are network of research institutions working on biodiversity and related topics, developed from EU-funded Networks of Excellence.

6 See http://www.epbrs.org.
} 
also active at the science-policy interface, though their role is often limited by lack of resources (e.g., European Ecological Federation and its national members, Society of Conservation Biology, European chapter of the Society for Ecological Restoration, the International Association of Landscape Ecology).

The analysis also pointed to major developments in the organization of networks and research programs at the global level. Some of these programs, such as GBIF and GEO BON, were linked via growing networks with European and national activities, but their role at the interface with society is still under development (Hobern et al. 2013; Geijzendorffer et al. 2015). Other global initiatives, such as the Future Earth programme, represent an explicit step towards this direction with a much broader thematic focus (Mauser et al. 2013; Future Earth 2014).

In addition to these mainly science-driven activities, European and international NGOs play an increasing role in providing knowledge-based advice and input into policy processes. IUCN has an international mandate for this, and NGOs like Birdlife and WWF (and many more) are regularly using in their policy work own data and knowledge as well as other sources.

Expertise in all science-policy processes comes mainly from individual experts of research institutes, universities and other knowledge holding organisations at national level. Links across the SPIs at national, European and international level are rarely established, but globally initiatives are ongoing. While European research funding has clearly linked the science communities across countries, these links are rarely established at the science-policy interface-apart from specific activities of some Networks of Excellence, international learned societies or the umbrella organisations of national academies (such as the European Academies Science Advisory Council EASAC and All European Academies ALLEA).

All these major SPIs are complemented by numerous ones with more restricted thematic or geographic focus. They include the interfacing activities of policy institutions such as the European Commission, which regularly invites experts to its meetings (e.g. DG Environment's working group on the implementation of the 2020 EU Biodiversity Strategy).

A new approach to improve the existing landscape needs to be carefully tailored to complement this wide array of existing activities and to minimize conflict of interests within and between existing institutions and initiatives, while contributing as much as possible to mainstreaming and coordinating these contributions (Nesshöver et al. 2014).

\section{Needs for improvement at the science-policy-interface}

Different actors in the policy context may need different information and knowledge (Balian et al. 2012), which requires adapted approaches and formats as stated in interviews and a focus group with policy-makers and practitioners (Balian et al. 2012; Young et al. 2013; Nesshöver et al. 2014). In addressing different user groups, there is a need to improve how the different SPIs and individual knowledge holders interact and in what ways they are enabled to make their knowledge available. In the consultation process, several requirements for successfully addressing the existing diversity of knowledge users were identified (KNEU Team 2014; Nesshöver et al. 2014):

- Joint formulation of questions and challenges between knowledge requesters and knowledge holders The process of jointly formulating questions between decisionmakers and knowledge holders may often be the most important part of science-policy 
interactions, as they facilitate mutual understanding and may yield early insights about what knowledge on the topic is actually available (Pullin et al. 2009). Without such a participatory approach early on in the process, expectations by policy-makers might diverge from the understanding of knowledge providers. There are a number of recent approaches for collaboratively identifying research needs (Sutherland et al. 2009; Dicks et al. 2013; Ingram et al. 2013; Jones et al. 2015) that could also further inform and support this joint formulation of questions requiring synthesis of existing knowledge (see below).

- Focus on knowledge for implementation and evaluation (policy design, monitoring and revision) Scientific outputs aimed at informing policies often remain at a overarching and strategic level, not taking into account the explicit needs and views of policy design and revision. Processes and knowledge outputs of the NoK on biodiversity and ecosystem services should take into account the challenges of feeding relevant and timely knowledge to the different phases of the policy cycle (namely policy design, monitoring and revision). Knowledge outputs should also include explicitly the knowledge of practitioners and managers to guarantee relevance.

- Production of concerted views from the knowledge community (cross- and intradisciplinary) Different interests or knowledge holder groups can present opposing or seemingly contradictory scientific evidence, particularly on contentious and/or emerging issues. Often this is caused by a combination of factors including a focus on only a part of a complex interaction, biased assumptions, or time and budget constraints. Failure to acknowledge and adequately address such potential biases can undermine the credibility of the scientific knowledge used and its usefulness for the policy questions at stake. The NoK on biodiversity and ecosystem services should include structures and processes that prevent inappropriate questions, help gain a clearer picture on available knowledge, make explicit the complex causal links as well as the uncertainties behind it, and outline the implications for different policy contexts.

- Timely advice and contact with relevant experts In many situations policy-makers need to respond very quickly. If they happen to know someone knowledgeable on the issue, they will often rely on his/her opinion-even though they are aware that the opinions of single experts might be biased (Dicks et al. 2014). When no expert is readily available, searching the internet might be the chosen option. Several of the interviewees stressed the usefulness of a "one-stop shop" where they could be sure to find relevant information and useful links (Balian et al. 2012).

- Horizon scanning and foresight Many activities have been undertaken recently to better scan for emerging issues, but these attempts were either focussed on specific topics (e.g., Sutherland et al. 2015) or, engaged in much broader perspectives (e.g. the foresight activities of the Joint Research Centre for Europe). In the biodiversity and ecosystem services context, an approach combining both hasn't been applied so far, but would be a helpful tool to create relevant outcomes (see for example Cook et al. 2014).

- Facilitate the identification of research needs Many questions arising from policy cannot be answered directly/sufficiently based on existing knowledge, but require additional research. To be able to timely provide new research-based knowledge, regular scoping activities identifying research gaps arising from policy needs should support the set-up of research programmes. Often, the compilation of knowledge on a particular subject via the functions mentioned above will identify major research gaps. As mentioned above this could also make use of recent collaborative identification of key research questions related to biodiversity and ecosystem services (Sutherland et al. 2009; Dicks et al. 2013; Ingram et al. 2013; Jones et al. 2015) 
Although various institutions currently address some of these needs, the consultation process pointed out that a networking approach could help to improve their links and provide a more coherent framing for interface activities. For example, the trial assessment that conducted a knowledge synthesis on management issues of floodplains brought together knowledge holders from science and management practice (Schindler et al. 2014). The consultations also showed, that the knowledge holder community is increasingly interested in getting engaged in SPI processes, and that they could benefit from a framework that allows them to identify the best way of getting active and build their capacity on SPI activities (see also Sect. 5).

\section{The Network of Knowledge approach, its functions and added value}

To complement the landscape of existing institutions and address the needs identified in the consultation, the Network of Knowledge would fulfil four interrelated functions: It would (A) address the knowledge needs of environmental policy-makers through the synthesis of relevant knowledge on a request-driven basis, (B) proactively contribute to policy on research and innovation by identifying upcoming research needs, $(\mathrm{C})$ enhance the networking capacity of existing institutions and facilitate engagement in SPI activities for

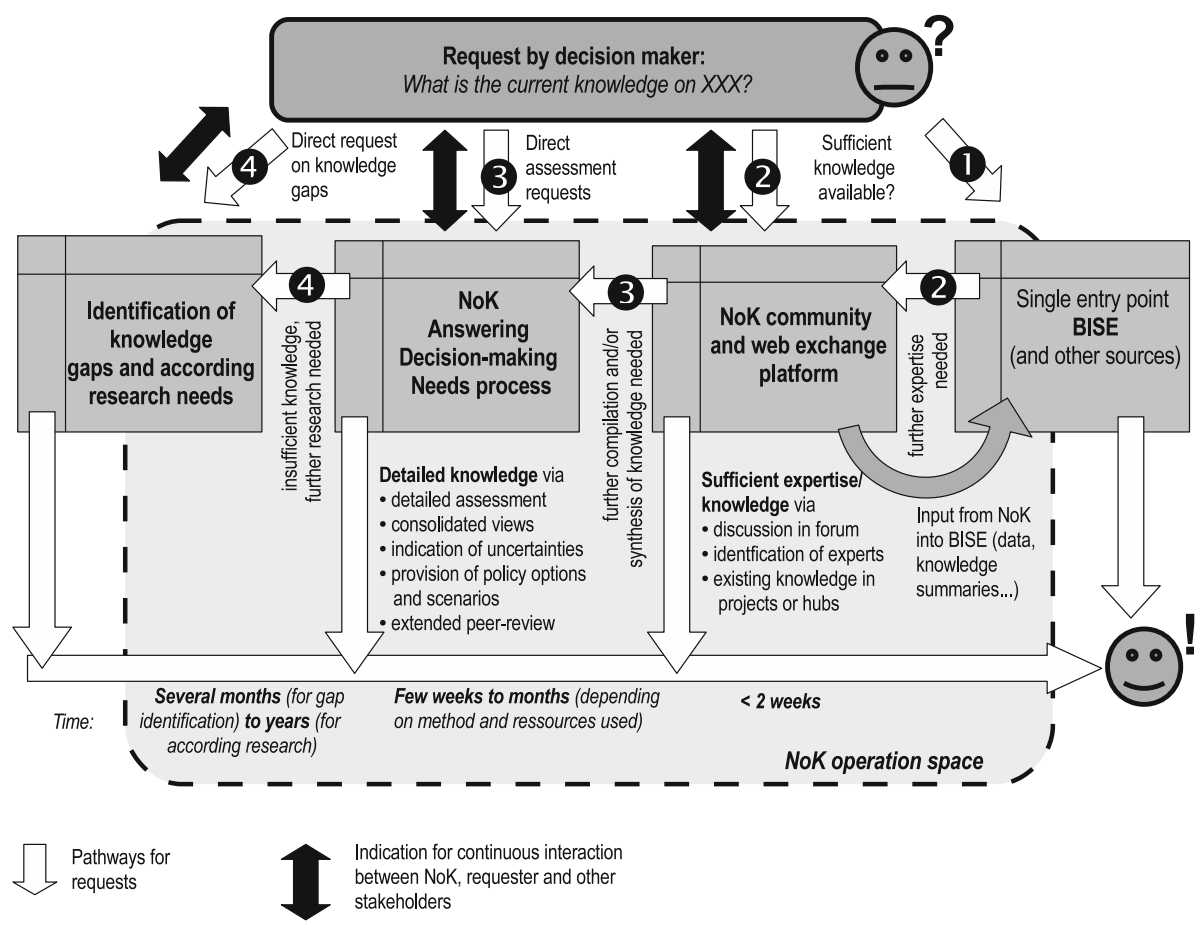

Fig. 1 Flowchart of the working methodology of a Network of Knowledge by indicating entry points where the Network of Knowledge is supposed to support decision making in identifying and collating relevant knowledge. Numbered arrows represent steps of logical pathways of knowledge search starting at simple questions that can be responded via web search to the most complex knowledge generation by conducting research 
individuals and their institutions, (D) link European networks to the international context, to ensure a European "added-value" for international developments. The developed four functions in the NoK are described in more detail below (see also Fig. 1).

\section{Knowledge synthesis function}

This function aims to contribute to decision-making by providing relevant knowledge on a request-driven basis. Whenever a topic requires an in-depth analysis and a consolidated view from the community of knowledge holders, specific activities to analyse and synthesize existing knowledge will be needed. A main characteristic of the approach developed is that it systematically envisages joint scoping of the questions with the requesters and other relevant actors. Based on this, knowledge holders from different scientific disciplines and other relevant experts, including practitioners and other knowledge holders, are identified and invited to jointly synthesize available knowledge on all the aspects specified (for details, see KNEU Team 2014; Livoreil et al. 2016; Schindler et al. 2016a). This may also include different levels of synthesis products, from broader reports to short synthesis paper and briefs, as for example described by Dicks et al. (2014). It may also include direct, short term contacts, as for example recently established by the OPPLA platform. $^{7}$

The added value of the developed NoK is to create a one-entry point for requests that need direct input from science but cannot currently easily be tackled via existing pathways. The NoK approach would also enable broad engagement of knowledge holders in synthesis activities, a factor largely missing from most current assessment processes (Beck et al. 2014; Vohland and Nadim 2015), and would be more flexible in accessing knowledge at appropriate scales (e.g. on the Member State level via local networks and institutions). Given the broad expertise in Europe for different methodologies to synthesize knowledge, the NoK would allow the use of a broad range of methodologies that go beyond the approach of writing of peer-reviewed reports and assessments (Pullin et al. 2016). Applied methodologies may include for instance systematic reviews (Pullin and Stewart 2006), short synthesis or briefs (Dicks et al. 2014), adaptive management frameworks (Armitage et al. 2007; Westgate et al. 2013), expert based approaches (see Bergmann et al. 2012 for an overview) or a combination of them. This diversity of potential methodologies was perceived as a major value of a NoK approach, as it allows for a better integration of different perspectives and types of knowledge (Tengö et al. 2014). However, this perception proved very difficult to achieve in practice in the trial assessments (Carmen et al. 2015).

Particularly when dealing with contentious issues, but also to establish credibility in general, it will be crucial that in addressing any given request, all knowledge synthesis processes are conducted and documented in an entirely transparent manner and open for a broad engagement from the start (Sarkki et al. 2013). Clear and transparent procedures should allow for a broad participation and open up to different perspectives in science and beyond (Young et al. 2014), while maintaining the advantages of scientific documentation and methodological rigor. For example, the protocols of systematic reviews will be made publicly available for comment before the review is conducted.

\footnotetext{
7 The "Ask OPPLA" function at http://oppla.eu/ask-oppla is a "crowd-sources enquiry service" that allows requesters to pose questions related to ecosystem services management and receive an answer within $48 \mathrm{~h}$ from suitable members of the community.
} 


\section{Research strategy function}

This function aims to identify upcoming policy-relevant research gaps and emerging issues and how the knowledge holders could be supported to address them. Although this function is currently provided by individual institutions for instance in the form of publishing sector specific research agendas, it could be greatly improved by facilitating a broader participation of experts and broadening the scope of topics beyond its narrow focus on biodiversity and ecosystem services. Besides identifying knowledge needs directly upon requests from policy-makers, a NoK would identify emerging issues from science and stakeholders via horizon scanning and other approaches (e.g., Sutherland et al. 2011).

When answering requests from decision-makers, research gaps and/or the need for further integration of data, infrastructure, and institutions will often be identified. Efficiency gains can therefore be achieved by linking the knowledge synthesis and the research strategy functions, especially for complex requests where different depths of existing knowledge are readily apparent. Linking both functions is also important for engaging researchers to join science-policy interactions. Having the possibility to point to further research needs derived from knowledge assessment processes has often been mentioned in the consultation as incentive increasing the motivation of researchers to participate in the Network of Knowledge.

\section{Networking and capacity building function}

This function aims at improving the existing networks of knowledge holders and plays a key role for the other functions. The added value of a NoK lies in its ability to identify and involve a much broader set of experts, over a wider thematic and geographic scope than most current SPIs. Networking should be understood in its broad sense and include a strong element of capacity building for enabling individuals to participate in activities on the other functions. Networking is necessary to strengthen the community of knowledge holders and to increase their ability to engage in structured approaches to integrate and synthesize knowledge from different sources, disciplines and sectors. Today, the limited opportunities for engagement of knowledge holders and decision makers in many SPI projects and processes is experienced as a major challenge for existing SPIs (Nesshöver et al. 2013; Bednarek et al. 2015) as verified with the trial assessments conducted to test the NoK (Schindler et al. 2016a).

This function contains an institutional dimension that addresses institutes, existing networks, learned societies and other knowledge holders to get them engaged in the wider network, as well as an individual dimension that addresses the capabilities of individual knowledge holders to get actively involved in interface activities (Görg et al. 2016).

Participants of the consultation process indicated that the added-value from this function include the strengthening and better linking of existing networks, as well as the possibility to better identify the relevant target audiences. Network approaches on the national scale (e.g. in the national biodiversity platforms in Belgium, France and Germany) have shown these ingredients to be essential for success at the SPI. Networking also further enhances collaboration and encourages openness in bringing together different disciplines and expertise across countries on a specific topic. Also, it makes the link between knowledge forms more explicit and enhances responsiveness, an issue seen already at the level of individual research projects (Nesshöver et al. 2013). 


\section{International collaboration function}

A NoK should support knowledge integration at the European level, enhancing collaboration and encouraging openness within Europe and beyond. In doing so, it would optimize the input of European knowledge in international science-policy processes and multilateral agreements (e.g. the Convention on Biological Diversity or IPBES), foster European links to global research efforts (e.g. Future Earth, GEOBON, GBIF), and at the same time profit from international inputs. To give an example of the potential of a NoK, it could facilitate regional activities planned/started within the IPBES work programme, e.g. the regional assessment on biodiversity and ecosystem services in Europe and Central Asia, expected to be finished in 2017. Regional inputs via regional networks that go beyond the IPBES internal process, such as a NoK, will be crucial to ensure credibility and relevance and may also help to translate back IPBES results into national/regional contexts (Beck et al. 2014).

\section{Integrated approach to functions}

To address this set of functions that summarized different elements discussed during the consultation, a Network of Knowledge would need to develop an integrated and active community of practice that supports knowledge-informed policy-making (Fig. 1, "NoK operation space"). Different kinds of requests could be addressed by these functions. If a knowledge requester (e.g., a policy-maker from the EU Commission) can gain a satisfactory answer via existing means, such as a search on the Biodiversity Information System for Europe (BISE) portal of the European Environment Agency (EEA) (white arrow $\mathbf{0}$ in Fig. 1), the NoK does not need to be invoked. If more knowledge is needed, the NoK might be mobilised with its knowledge synthesis function, to call for further expertise, e.g. specific experts to help, or point to synthesis or reviews already available to meet the request (2). If an even more detailed assessment of knowledge is needed, new synthesis processes could be set up (3). If the available knowledge proves insufficient and further research is needed (or the request directly addresses research needs), the research strategy function of the NoK would then be addressed (4). All of these steps are valid for Europeanscale questions, or for questions of international collaboration, for example in the context of the Convention of Biological Diversity or IPBES.

\section{Discussion}

Form the consultation it became clear that addressing the diverse needs at the sciencepolicy-interface in an integrated way, as outlined with the NoK approach, poses a number of challenges with respect to maximizing credibility, relevance and legitimacy, as in many other interface processes (Koetz et al. 2012; Sarkki et al. 2013). But from the consultation we also see potentials strengths of the integrated NoK approach to address them.

\section{Challenges for credibility, relevance and legitimacy in a Network of Knowledge}

The consultations in the project led to the identification of five essential issues for developing a credible, relevant and legitimate NoK that fulfils the four functions described above: quality assurance; data standards and sharing; connecting, motivating and acknowledging the knowledge holders and requesters involved; communication; and 
capacity building. All these issues are strongly interlinked and must be addressed in an integrated manner. Many of them are, of course, a challenge to SPIs in general.

Quality assurance in SPIs covers a broad range of issues, some of them directly tied to scientific work (see also next section on data standards) and others related to the SPI process, where quality stands for effective and transparent procedures and ensures credibility. The NoK approach enables independent internal and external feedback loops and other means for evaluating and increasing quality. Particularly for conflicting issues, linking the different perspectives into a common process can help to bring more knowledge into the decision-making process and make the underlying conflicts explicit.

The NoK approach includes an explicit choice of the best available methodologies to compile and assess the available evidence for addressing requests from policy (see KNEUTeam 2014, Pullin et al. 2016). This ranges from evidence-focused methodologies such as systematic reviews to different forms of moderated expert consultations to transdisciplinary approaches such as collaborative adaptive management, with the possibility to combine these approaches depending on the needs identified (Pullin et al. 2016; Schindler et al. 2016a). The choice process will be made transparent through pre-established protocols that lay out the circumstances under which each the methods is recommended, as well as their strengths and limitations, and required type of information, expert involvement and resources.

Despite recent improvements (e.g. by GBIF, LifeWatch, LTER and EUBON/GEO$\mathrm{BON}$ ), answering questions and producing knowledge that require interpretation of biodiversity data is still hampered by lack of harmonized, reliable and publicly-accessible databases. The lack of agreement in relatively simple matters, such as the use of standardized protocols, can result in multiple experts disagreeing with each other already at the data integration level (Bendix et al. 2012; Enke et al. 2012). This is a serious constraint to transparent and easy-to-understand communication with requesters at a later stage of knowledge compilation, and may weaken the credibility of the information provided by the scientific community. The reluctance of many researchers to openly share data often arises from complex issues like confidentiality, ownership (data owners often do not agree to publish their data due to legal issues), or data sensitivity (red list data for instance), and may severely hinder the timely and constant integration of new data into shared databases (Moritz et al. 2011; Enke et al. 2012). This underlying challenge cannot be tackled directly by the NoK, but rather by specialized processes in science like GBIF, LifeWatch, LTER and GEOBON, or through specific agreements between science, environmental agencies (or other continuously working institutions), and sometimes society (e.g. in the context of citizen science). It will, however, remain an obstacle for better informed policy-making in both science as well as in policy, and preclude the use of data-demanding methods to analyze existing knowledge (Wetzel et al. 2015).

In today's science as well as in the policy world, lack of time is the most crucial constraint for getting engaged in interface activities (Nesshöver et al. 2013; Sarkki et al. 2013). Many experts raised this concern during the consultations. At the same time, participation reached a critical mass in many processes, as soon as potential benefits (for a "higher" target such as better biodiversity policy, as well as personal targets such as learning via involvement) became clear and experts were addressed directly (Carmen et al. 2015; Schindler et al. 2016a). Nonetheless, acknowledgment of science-policy activities of experts in their institutions and by funders and policy are still seen as a challenge and must be strengthened as one aspect of expert performance in order to raise the profile and acceptance of such work (Carmen et al. 2015). 
The main challenge is then to connect enough knowledge holders for a comprehensive representation of the existing disciplinary and interdisciplinary knowledge on a topic that is going to be tackled. To enhance credibility and legitimacy, the NoK will have to work in a complementary process of networking people with excellent skills and the latest knowledge as well as integrating different types of knowledge. Involving well-known and respected contributors will improve visibility and credibility, but the processes should incorporate mechanisms to remain open to new, less experienced contributors to ensure capacity building (see below). In addition, continuity in the commitment from the community of interest will be required to ensure long-term functioning of the mechanism.

A NoK approach-through explicitly reaching out to the whole community across knowledge types, disciplines, regions and backgrounds-has a clear added value with regard to credibility, relevance and legitimacy as it can reach out in a timely and efficient manner to relevant expertise and enables broader participation in terms of knowledge types and sources (Carmen et al. 2015). This is rarely the case in many science-policy approaches that restrict the input to certain groups, institutions or individuals, such as most consultancy contracts and research projects. Of course, there is a trade-off between enlarging the potential relevant expertise and ensuring credibility through a restricted number of high-level experts. In specific situations, the credibility of the knowledge produced relies more predominantly on direct evidence than on perceived inclusion of a wider science or policy context. The added value of the NoK lies in the open and transparent way in which such trade-offs are addressed and that the choice is made in relation to the needs and requirements of the requesters.

Meet the challenges outlined above will require a high level of effective two-way communication on issues such as policy needs, processes of the NoK, data and methodologies. This is especially true at the initial phases of the NoK, when the approach and its procedures (Fig. 1) will be new to most actors, particularly since it requires a high level of understanding of the different processes and does not always follow "classical" approaches of science-policy interactions. Communications in the NoK will need to balance the needs of communicating results, engaging people and fostering capacity building.

This holds especially true as many biodiversity and ecosystem service related issues are cross-sectoral issues (Tittensor et al. 2014), so a continuous broad outreach is needed to engage and make aware the relevant knowledge holders and requesters from all areas, including other policy sectors (e.g., agriculture, forestry, fisheries, climate and transport, finance) as well as different scientific disciplines (Jolibert and Wesselink 2012; Young et al. 2014). Here, a major challenge lies in the translation of problems to be tackled and the results achieved into the language and mindset of those sectors and disciplines. This will require dialogue with the policy 'requesters' to understand their needs in terms of process and outputs from the NoK, which appears to be one of the biggest challenge as the trial assessments have shown (Schindler et al. 2016a).

Building capacity at the science-policy interface, especially through the networking function, involves developing understanding, fostering trust, creating new links, applying new skills and developing shared knowledge. Hence, it is a process that may influence attitudes, behaviors and actions of individuals, institutions and the system as a whole (Cash et al. 2003; van den Hove 2007). Skills such as facilitation and conflict resolution may be crucial to implementing the NoK processes and should be a key component of its capacity building program (Nesshöver et al. 2013). Training in understanding the policy- and decision-making processes are also essential for experts getting involved in NoK processes-particularly those originating from the scientific community, where major misunderstandings still prevail regarding policy processes (Pielke 2007). 
Expert groups working in the NoK will include a wide range of perspectives, skills, expertise and knowledge sources from the start, requiring the building of capacities of experts facing different languages, theories and methodologies being from social sciences or natural sciences (see for example Tengö et al. 2014). A key challenge of the NoK will be to ensure the building of some common grounds and trust among all experts and actors engaged in the processes. As such, it will require support not only from funders, but also strengthening links with all kinds of knowledge hubs-organisations, networks and initiatives - at both the European and the national levels. A process of reflection and learning must be central to the NoK to help build bridges and reduce gaps between groups and move ever closer to collaborative working and information sharing (Carmen et al. 2015).

\section{Strengths of a Network of Knowledge}

Based on the consultations carried out and resulting identification of needs and requirements, we suggest that the NoK approach is an appropriate option to address several obstacles facing current science-policy interactions on complex issues like biodiversity and ecosystem services. These include a broader stakeholder involvement, the potential to include different forms of knowledge (if needed) and the flexibility and transparency in using synthesis methods. (UNEP 2009; Koetz et al. 2012; Beck et al. 2014). The potential strengths of the NoK approach are highlighted below and further elaborated in other contributions to this Special Issue:

- Integration of "networking" and "working" Following the approach of trans- and interdisciplinarity and jointly developing relevant knowledge across knowledge domains, the NoK approach explicitly links the issue of networking with the actual work on synthesising existing knowledge and identifying research needs. Inherently this involves power dynamics on one hand and the need for participation and openness on the other (see also Tremblay et al. 2016).

- Transparency and openness throughout processes The NoK approach will only work if transparency and openness are major elements. Decision as well as work processes need to be as transparent as possible, including the choice of methods used in knowledge assessments, the persons and institutions involved, and the potential reviews of activities. A single communication strategy addressing these different aspects might be of great help here. It could also help raising awareness on the need for improved communication of complex environmental topics. In terms of credibility, this is a major issue that requires dedicated resources including dedicated intermediaries as experts for such processes (Bednarek et al. 2015).

- Flexibility of methodological approaches European experts share a broad set of knowledge synthesis methods, and thus can adapt synthesis work to the types of questions posed and the quality and amount to knowledge available. To our knowledge, such a toolbox of methods has not been used in a coherent manner for science-policyinterfacing in the environmental sector (see also Pullin et al. 2016). By making such an overview available, the NoK can also stress the value of methods already in wide use (e.g., systematic reviews) and how they can be complemented by newer ones.

- Reflexivity and iterativity. In complex situations and settings, the attributes of credibility, relevance and legitimacy might not be enough to properly describe and analyse whether an SPI functions in a desired way (Heink et al. 2015, Sarkki et al. 2015). Rather, an additional attribute might be needed, that includes the learning process within an SPI and its intention to systematically improve its internal processes, 
so that it remains flexible and reflexive about its work. Sarkki et al. (2015) describe this attribute as iterativity. The NoK approach integrates this idea in its work and captures the importance (perceived by experts in the consultation) of ensuring capacity building and learning on processes. From a governance perspective, this could be included in a process of continuous formative evaluation, which should be embedded in the network processes and continuously informing and updating their functioning (see also Görg et al. 2016).

- Independence versus strong mandate In the consultation, the issue of independence of the Network of Knowledge and its work from policy and other stakeholders was perceived as extremely important. Many experts consulted stressed that the work should be independent of vested interests. At the same time, it was recognized that a strong political mandate, and thus also a strong role of specific policy-makers (or institutions) would be important, not the least in terms of motivation of experts to get involved. However, also in this case, political independence must be ensured.

- Governance model To address the challenges outlined, a proper governance model of the NoK will be crucial (KNEU Team 2014). Governance needs to involve institutions from the network, as well as individual experts, and balance the contrasting interests attached to different knowledge-holder groups, to allow for a maximum of potential engagement and transparency (see Görg et al. 2016).

The experience of the KNEU project, including the remaining contributions to this Special Issue, indicates that a NoK model could be suitable to address the most pressing needs of the science-policy interface on biodiversity and ecosystem services, complementing and even making use of existing SPI approaches. Such model is to some extent, the only appropriate one considering the specific European situation, with a high number of experts already engaged in pre-existing networks, including several SPIs, and a broad array of approaches and methodologies already available to assess knowledge. Yet, such a model requires that all actors work in a novel, more open, flexible and transparent manner that is often called for in discussion on the future knowledge society (Felt et al. 2007; Cornell et al. 2013). For decision-makers, it would yield a new, flexible access to existing knowledge which would be complementary to existing channels. For the biodiversity and ecosystem services research community it means further work on developing networks as well as getting engaged even more in the science-policy interface and thus raising the profile and the policy uptake of their work.

Acknowledgments The KNEU project was funded by the 7th Framework Programme of the European Commission (Contract No. 265299). We thank the numerous experts and stakeholders that participated in the project's activities, its workshop, conferences, survey, questionnaires and test cases. The authors also thank all project partners in the KNEU partners from the following institutions: UFZ (Germany), NERCCEH (UK), RBINS (Belgium), CIIMAR (Portugal), NIOZ (Netherlands), FRB (France), ALTERRA (Netherlands), University of Vienna (Austria), NINA (Norway), CSIC (Spain), MTA (Hungary), ECNC (Netherlands), Bangor University (UK), INBO (Belgium), EAA (Austria), SYKE (Finland), BEC (Ireland) and VLIZ (Belgium). I.R.G. was partly funded by the EU BON project (EU FP 7 Grant No. 308454) and contributes to the Labex OT-Med (No. ANR-11-LABX-0061) funded by the French Government through the A*MIDEX Project (No. ANR-11-IDEX-0001-02).

Open Access This article is distributed under the terms of the Creative Commons Attribution 4.0 International License (http://creativecommons.org/licenses/by/4.0/), which permits unrestricted use, distribution, and reproduction in any medium, provided you give appropriate credit to the original author(s) and the source, provide a link to the Creative Commons license, and indicate if changes were made. 


\section{References}

Araújo RM et al (2016) Status, trends, drivers and effects of change of kelp forests in Europe: a comprehensive expert consultation study. Biodivers Conserv. doi:10.1007/s10531-016-1141-7

Armitage D, Berkes F, Doubleday N (2007) Adaptive co-management: collaboration, learning and multilevel governance. UBC Press, Vancouver

Balian E, Berhault A, Jones-Walters L, Torre-Martin A, Nesshöver C, Vandewalle M (2012) Overview of experts and requesters of a potential NoK: mapping knowledge holders, identifying requesters and barriers on how to link them (Deliverable 1.1). http://biodiversityknowledge.eu/images/Documents/ Deliverables/KNEU-D1-1_clientsandholdersoverviewandbarriers_Final.pdf. Accessed 8 April 2016

Beck S et al (2014) Towards a reflexive turn in the governance of global environmental expertise the cases of the IPCC and the IPBES. Gaia 23:80-87

Bednarek AT, Shouse B, Hudson CG, Goldburg R (2015) Science-policy intermediaries from a practitioner's perspective: the Lenfest Ocean Program experience. Sci Public Policy. doi:10.1093/scipol/ scv008

Bendix J, Nieschulze J, Michener WK (2012) Data platforms in integrative biodiversity research. Ecol Inform 11:1-4. doi:10.1016/j.ecoinf.2012.04.001

Bergmann M, Jahn T, Knobloch T, Krohn W, Pohl C, Faust RC (2012) Methods for transdisciplinary research: a primer for practice. Campus Verlag, Frankfurt

Carmen E, Nesshöver C, Saarikoski H, Vandewalle M, Watt A, Wittmer H, Young J (2015) Creating a biodiversity science community: experiences from a European Network of Knowledge. Env Sci Pol 54:497-504

Cash DW et al (2003) Knowledge systems for sustainable development. Proc Natl Acad Sci 100:8086-8091

Cook CN, Inayatullah S, Burgman MA, Sutherland WJ, Wintle BA (2014) Strategic foresight: how planning for the unpredictable can improve environmental decision-making. Trends Ecol Evol 29:531-541. doi:10.1016/j.tree.2014.07.005

Cornell S et al (2013) Opening up knowledge systems for better responses to global environmental change. Env Sci Pol 28:60-70. doi:10.1016/j.envsci.2012.11.008

Dicks LV et al (2013) What do we need to know to enhance the environmental sustainability of agricultural production? A prioritisation of knowledge needs for the UK food system. Sustainability 5:3095-3115

Dicks LV et al (2014) A transparent process for "Evidence-Informed" policy making. Cons Lett 7:119-125. doi:10.1111/conl.12046

Dicks LV et al (2016) What works in conservation? Using expert assessment of summarised evidence to identify practices that enhance natural pest control in agriculture. Biodivers Conserv. doi:10.1007/ s10531-016-1133-7

Durham E, Baker H, Smith M, Moore E, Morgan V (2014) The BiodivERsA stakeholder engagement handbook. BiodivERsA, Paris

Enke N, Thessen A, Bach K, Bendix J, Seeger B, Gemeinholzer B (2012) The user's view on biodiversity data sharing-investigating facts of acceptance and requirements to realize a sustainable use of research data. Ecol Informatics 11:25-33

EPBRS (2009) Concept note: Network of Knowledge for biodiversity governance. European Platform for Biodiversity Research Strategy, Brussels. http://www.epbrs.org/PDF/2009\%2009\%2010\%20Concept $\% 20$ note $\% 20$ on $\% 20$ the\%20network\%20of\%20knowledge_version\%202-1.pdf Accessed 8 April 2016

Felt U, Wynne B, Stirling A, Callon M, Goncalves ME (2007) Science and governance: taking European knowledge society seriously. European Commission, Brussels. http://ec.europa.eu/research/sciencesociety/document_library/pdf_06/european-knowledge-society_en.pdf Accessed 11 November 2015

Funtowicz SO, Ravetz JR (1994) Uncertainty, complexity and post-normal science. Environ Toxicol Chem 13:1881-1885

Future Earth (2014) Strategic research Agenda-priorities for a global sustainability research strategy. ICSU, Paris

Geijzendorffer IR et al (2015) Bridging the gap between biodiversity data and policy reporting needs: an Essential Biodiversity Variables perspective. J Appl Ecol. doi:10.1111/1365-2664.12417

Görg C et al (2016) The governance of science-policy interfaces-Network vs. Platform approach. Biodivers Conserv. doi:10.1007/s10531-016-1132-8

Hauck J, Stein C, Schiffer E, Vandewalle M (2015) Seeing the forest and the trees: facilitating participatory network planning in environmental governance. Glob Environ Change 35:400-410

Heink U et al (2015) Conceptualizing credibility, relevance and legitimacy for evaluating the effectiveness of science-policy interfaces: challenges and opportunities. Sci Pub Pol 43:676-689. doi:10.1093/ scipol/scu082 
Henle K et al (2010) Securing the conservation of biodiversity across administrative levels and spatial, temporal, and ecological scales-research needs and approaches of the SCALES project. Gaia 19:187-193

Hobern D et al (2013) Global biodiversity informatics outlook: delivering biodiversity knowledge in the information age. Global Biodiversity Information Facility (Secretariat), Copenhagen

Hoffmann A et al (2014) Improved access to integrated biodiversity data for science, practice, and policythe European Biodiversity Observation Network (EU BON). Nat Conserv 6:49-65

Ingram JS et al (2013) Priority research questions for the UK food system. Food Secur 5:617-636

Jolibert C, Wesselink A (2012) Research impacts and impact on research in biodiversity conservation: the influence of stakeholder engagement. Env Sci Pol 22:100-111. doi:10.1016/j.envsci.2012.06.012

Jones AC et al (2015) Prioritization of knowledge needs for sustainable aquaculture: a national and global perspective. Fish Fish 16:668-683

Jongman R (2013) Biodiversity observation from local to global. Ecol Ind 33:1-4

Koetz T, Farrell KN, Bridgewater P (2012) Building better science-policy interfaces for international environmental governance: assessing potential within the Intergovernmental Platform for Biodiversity and Ecosystem Services. Int Environ Agreem 12:1-21

KNEU Team (2014) A recommended design for "BiodiversityKnowledge", a Network of Knowledge to support decision making on biodiversity and ecosystem services in Europe. Leipzig. http:// biodiversityknowledge.eu/images/PDF/WhitePaper_web.pdf Accessed 11 November 2015

Livoreil B et al (2012) Prototype NOK mechanism (Deliverable 2.1 of the KNEU project). KNEU Project, Leipzig. http://www.biodiversityknowledge.eu/images/Documents/Deliverables/KNEU-D2-1NoKpro totype.pdf Accessed 11 Nov 2015

Livoreil B, Geijzendorffer IR, Pullin AS, Schindler S, Vandewalle M, Nesshöver C (2016) Biodiversity knowledge synthesis at the European scale: actors and steps. Biodivers Conserv. doi:10.1007/s10531016-1143-5

Mauser W, Klepper G, Rice M, Schmalzbauer BS, Hackmann H, Leemans R, Moore H (2013) Transdisciplinary global change research: the co-creation of knowledge for sustainability. Curr Opin Environ Sustain 5:420-431

Moritz T et al (2011) Towards mainstreaming of biodiversity data publishing: recommendations of the GBIF Data Publishing Framework. Task Group BMC Bioinform 12:S1

Nesshöver C, Müssner R, Henle K, Pinto IS (2008) Linking biodiversity research and policy in Europe. Ambio 37:138-141

Nesshöver C et al (2014) Summary report and recommendations on Improving the Science-Policy Interface for Biodiversity and Ecosystem Services in Europe (contract: Ref No 07-0307/2013/661961/SER/B2). Leipzig http://ec.europa.eu/environment/nature/knowledge/pdf/EU\%20Mechanism\%20Summary\%20 Report\%202015.pdf Accessed 11 Nov 2015

Nesshöver C et al (2013) Improving the science-policy interface of biodiversity research projects. Gaia 22:99-103

Pielke RA (2007) The honest broker: making sense of science in policy and politics. Cambridge Univ Press, Cambridge

Pullin AS, Stewart GB (2006) Guidelines for systematic review in conservation and environmental management. Conserv Biol 20:1647-1656

Pullin AS, Knight TM, Watkinson AR (2009) Linking reductionist science and holistic policy using systematic reviews: unpacking environmental policy questions to construct an evidence-based framework. J Appl Ecol 46:970-975

Pullin AS et al (2016) Selecting appropriate methods of knowledge synthesis to inform biodiversity policy. Biodivers Conserv. doi:10.1007/s10531-016-1131-9

Sarkki S, Niemelä J, Tinch R, van den Hove S, Watt A, Young J (2013) Balancing credibility, relevance and legitimacy: a critical assessment of trade-offs in science-policy interfaces. Sci Public Policy 41:194-206. doi:10.1093/scipol/sct046

Sarkki S et al (2015) Adding 'iterativity’ to the credibility, relevance, legitimacy: a novel scheme to highlight dynamic aspects of science-policy interfaces. Env Sci Pol 54:505-512

Schindler S et al (2016a) The network Biodiversity Knowledge in practice: insights from three trial assessments. Biodivers Conserv. doi:10.1007/s10531-016-1128-4

Schindler S et al (2016b) Multifunctional floodplain management and biodiversity effects: lessons from six European countries. Biodivers Conserv. doi:10.1007/s10531-016-1129-3

Schindler S et al (2014) Multifunctionality of floodplain landscapes: relating management options to ecosystem services. Landsc Ecol 29:229-244. doi:10.1007/s10980-014-9989-y

Settele J et al (2005) ALARM: assessing LArge-scale environmental risks for biodiversity with tested methods. Gaia 14:69-72 
Spierenburg M (2012) Getting the message across biodiversity science and policy interfaces-a review. Gaia 21:125-134

Sutherland W et al (2009) One hundred questions of importance to the conservation of global biological diversity. Conserv Biol 23:557-567

Sutherland WJ, Fleishman E, Mascia MB, Pretty J, Rudd MA (2011) Methods for collaboratively identifying research priorities and emerging issues in science and policy. Meth Ecol Evol 2:238-247

Sutherland WJ et al (2014) Solution scanning as a key policy tool: identifying management interventions to help maintain and enhance regulating ecosystem services. Ecol Soc. doi:10.5751/ES-06082-190203

Sutherland WJ et al (2015) A horizon scan of global conservation issues for. TREE 30:17-24. doi:10.1016/j. tree.2014.11.002

Tengö M, Brondizio ES, Elmqvist T, Malmer P, Spierenburg M (2014) Connecting diverse knowledge systems for enhanced ecosystem governance: the multiple evidence base approach-. Ambio 43:579-591. doi:10.1007/s13280-014-0501-3

Tremblay M, Vandewalle M, Wittmer H (2016) Ethical challenges in an open system: the Network of Knowledge's ethical risks assessment and its ethical infrastructure. Biodivers Conserv. doi:10.1007/ s10531-016-1123-9

UNEP (2009) Gap analysis for the purpose of facilitating the discussions on how to improve and strengthen the science-policy interface on biodiversity and ecosystem services (UNEP/IPBES/2/INF/1). UNEP, Nairobi

UNEP (2010) Report of the third ad hoc intergovernmental and multi-stakeholder meeting on an intergovernmental science-policy platform on biodiversity and ecosystem services ("Busan Outcome")— UNEP/IPBES/3/3. UNEP, Nairobi. http://www.ipbes.net/images/stories/documents/K1061514_IPB ES-3-3-REPORT.pdf Accessed 11 Nov 2015

van den Hove S (2007) A rationale for science-policy interfaces. Futures 39:807-826. doi:10.1016/j.futures. 2006.12.004

van der Sluijs JP, van Est R, Riphagen M (2010) Beyond consensus: reflections from a democratic perspective on the interaction between climate politics and science. Curr Opin Env Sust 2:409-415. doi:10.1016/j.cosust.2010.10.003

van der Sluijs JP et al (2015) Conclusions of the Worldwide Integrated Assessment on the risks of neonicotinoids and fipronil to biodiversity and ecosystem functioning. Environ Sci Pollut Res 22:148-154. doi:10.1007/s11356-014-3229-5

Vohland K, Nadim T (2015) Ensuring the success of IPBES: between interface, market place and parliament. Philos T R Soc B 370:1662. doi:10.1098/rstb.2014.0012

Walters K (2013) Data, data everywhere but we don't know what to think? Neonicotinoid insecticides and pollinators. Outlooks on Pest Management 24:151-155. doi:10.1564/v24_aug_02

Westgate MJ, Likens GE, Lindenmayer DB (2013) Adaptive management of biological systems: a review. Biol Conserv 158:128-139. doi:10.1016/j.biocon.2012.08.016

Wetzel FT et al (2015) The roles and contributions of Biodiversity Observation Networks (BONs) in better tracking progress to 2020 biodiversity targets: a European case study. Biodiversity 16:137-149. doi:10. 1080/14888386.2015.1075902

Young JC, Watt AD, van den Hove S, SPIRAL Project Team (2013) Effective interfaces between science, policy and society: the SPIRAL project handbook. http://www.spiral-project.eu/content/documents/ Accessed 8 April 2016

Young JC et al (2014) Improving the science-policy dialogue to meet the challenges of biodiversity conservation: having conversations rather than talking at one-another. Biodivers Conserv 23:387-404 